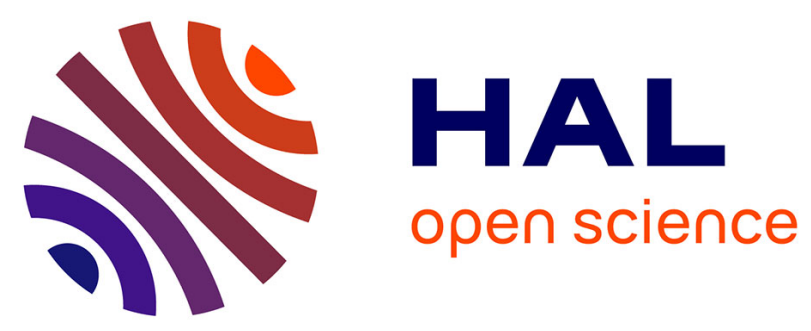

\title{
Photosystem II cycle activity and alternative electron transport in the diatom Phaeodactylum tricornutum under dynamic light conditions and nitrogen limitation
} Heiko Wagner, Torsten Jakob, Johann Lavaud, Christian Wilhelm

\section{- To cite this version:}

Heiko Wagner, Torsten Jakob, Johann Lavaud, Christian Wilhelm. Photosystem II cycle activity and alternative electron transport in the diatom Phaeodactylum tricornutum under dynamic light conditions and nitrogen limitation. Photosynthesis Research, 2015. hal-01236470

\author{
HAL Id: hal-01236470 \\ https://hal.science/hal-01236470
}

Submitted on 1 Dec 2015

HAL is a multi-disciplinary open access archive for the deposit and dissemination of scientific research documents, whether they are published or not. The documents may come from teaching and research institutions in France or abroad, or from public or private research centers.
L'archive ouverte pluridisciplinaire HAL, est destinée au dépôt et à la diffusion de documents scientifiques de niveau recherche, publiés ou non, émanant des établissements d'enseignement et de recherche français ou étrangers, des laboratoires publics ou privés. 
Title

Photosystem II cycle activity and alternative electron transport in the diatom Phaeodactylum tricornutum under dynamic light conditions and nitrogen limitation

Heiko Wagner ${ }^{\mathrm{a}}$, Torsten Jakob ${ }^{\mathrm{a}^{*}}$, Johann Lavaud $^{\mathrm{b} \$}$, Christian Wilhelm $^{\mathrm{a}, \mathrm{c}}$

${ }^{a}$ University of Leipzig, Department of Biology, Johannisallee 21-23, D-04103 Leipzig, Germany

bUMRi 7266 'LIENSs', CNRS/University of La Rochelle, Institute for Coastal Research and Environment (ILE), 2 rue Olympe de Gouges, 17000 La Rochelle cedex, France

${ }^{\mathrm{c}}$ German Centre for Integrative Biodiversity Research (iDiv) Halle-Jena-Leipzig, Deutscher Platz 5e, D-04103 Leipzig, Germany

* Corresponding author. University of Leipzig, Department of Biology, Johannisallee 21-23, D-04103 Leipzig, Germany. Tel.: +49 341 9736873. E-mail address: tjakob@ rz.uni-leipzig.de

\$ Current address: UMI 3376 TAKUVIK, CNRS/University Laval, Department of Biology, Pavillon Alexandre-Vachon, 1045 avenue de la Médecine, Québec (Québec) G1V 0A6, Canada

\section{Keywords:}

Diatom, cyclic electron transport, non-photochemical quenching, macromolecular composition, FTIR spectroscopy

\section{Abbreviations:}

AET, alternative electron transport ; $\mathrm{CET}_{\mathrm{PSII}}$, cyclic electron transport around Photosystem II, NPQ, non-photochemical quenching ; PQ, plastoquinone ; SL, sinusoidal light 


\begin{abstract}
Alternative electron sinks are an important regulatory mechanism to dissipate excessively absorbed light energy particularly under fast changing dynamic light conditions. In diatoms, the cyclic electron transport (CET) around Photosystem II (PS II) is an alternative electron transport pathway (AET) that contributes to avoidance of overexcitation under high light illumination. The combination of nitrogen limitation and high intensity irradiance regularly occurs under natural conditions and is expected to force the imbalance between light absorption and the metabolic use of light energy. The present study demonstrates that under N-limitation the amount of AET and the activity of $\mathrm{CET}_{\mathrm{PSII}}$ in the diatom Phaeodactylum tricornutum was increased. Thereby, the activity of $\mathrm{CET}_{\mathrm{PSII}}$ was lineary correlated with the amount of AET rates. It is concluded that $\mathrm{CET}_{\mathrm{PSII}}$ significantly contributes to AET in $P$. tricornutum. Surprisingly, $\mathrm{CET}_{\mathrm{PSII}}$ was found to be activated already at the end of the dark period under N-limited conditions. This coincided with a significantly increased degree of reduction of the plastoquinone (PQ) pool. The analysis of the macromolecular composition of cells of P. tricornutum under N-limited conditions revealed a carbon allocation in favour of carbohydrates during the light period and their degradation during the dark phase. A possible linkage between the activity of $\mathrm{CET}_{\mathrm{PSII}}$ and degree of reduction of the PQ pool on the one side and the macromolecular changes on the other is discussed.
\end{abstract}




\section{Introduction}

Marine ecosystems can be highly dynamic systems where phytoplankton is exposed to wide variations of abiotic factors, e.g. light, nutrient availability, and temperature (Raven and Geider, 2003). The dynamics of abiotic factors thus, drive changes in the phytoplankton community structure (e.g. Dimier et al., 2007). Diatoms are known to outcompete other phytoplankton groups in nutrient-rich and turbulent waters (e.g. Falkowski et al., 2004) where a large flexibility of the photosynthetic apparatus is required. It is assumed that diatoms profit from their large photoprotective potential under these conditions. Particularly, the rapidly inducible non-photochemical quenching (NPQ) of excess energy is considered as an important regulatory mechanism of photochemistry in diatoms (Grouneva et al., 2008; Lavaud \& Goss, 2014). The major component of NPQ in diatoms is the energy-dependent quenching which almost solely depends on the degree of de-epoxidation of the xanthophyll-cycle (XC) pigment diadinoxanthin to diatoxanthin (Goss \& Jakob, 2010).

Besides NPQ, the dissipation of excess energy could be also accomplished via alternative electron-cycling pathways. In diatoms, these pathways should include the Mehler reaction (Claquin et al., 2004), cyclic electron transport around PSI (Grouneva et al., 2009) and

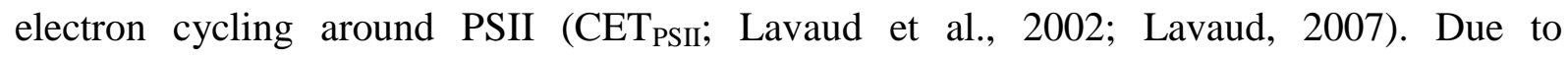
methodological constraints the extent of the respective electron pathways in diatoms under different growth conditions is largely unknown.

Interestingly, in diatoms the reduction of nitrate in excess of metabolic demand comes into play as an additional alternative electron sink under specific conditions (reviewed in Allen 2005). Lomas \& Glibert (1999) documented the uncoupling of uptake and reduction of nitrate in relation to cellular demands in natural diatom-dominated phytoplankton assemblages under conditions of high irradiance and low temperatures. They concluded that nitrate can serve as a terminal electron sink to balance the cellular energy budget. Therefore it is likely to assume that nitrogen limitation or starvation causes a specific challenge of acclimation for diatoms. 
Another pecularity of diatoms is the presence of a complete urea cycle (Armbrust et al., 2004; Bowler et al., 2008). Whereas in heterotrophic organisms this cycle commonly serves to dispose excess ammonium, in diatoms, the urea cycle may function as temporary energy storage, for recycling and biosynthesis of organic nitrogen compounds (Allen et al., 2011), and for metabolic $\mathrm{N}$ and $\mathrm{C}$ resdistribution (Bender et al., 2012) particularly in response to episodic nitrogen availability. In a recent study it was shown that the proteins of the nitrogen assimilation pathway and of the urea cycle contain redox-sensitive thiols that respond to oxidative stress conditions (Rosenwasser et al., 2014). Since the expression of the nitrate reductase gene in algae is redox-regulated via the redox state of the plastoquinone (PQ) pool (Giordano et al., 2005) it was proposed that the regulation of nitrogen metabolism responds to the redox state of the chloroplast and is important for the metabolic plasticity to ensure cellular homeostasis in diatoms particularly under nitrogen stress conditions.

Nitrogen is an essential nutrient for the biosynthesis of amino acids and proteins, nucleic acids and chlorophyll (Chl). Therefore, nitrogen limitation or starvation forces photosynthetic cells to readjust the balance between energy supply by light absorption and the primary photosynthetic reaction on the one hand and energy usage by the cellular metabolism on the other (Geider et al., 1998). Typically, cells react with a decrease of cellular Chlorophyll (Chl) content to lower the amount of absorbed radiation (e.g., Geider et al., 1998; Jakob et al., 2007). In addition, the limited availability of nitrogen for protein synthesis requires a rearrangement of the macromolecular composition. Here, it has to be differentiated between conditions of $\mathrm{N}$-limitation and $\mathrm{N}$ starvation. Under $\mathrm{N}$ starvation (continuous depletion of nitrogen in the surrounding medium) diatom cells typically accumulate lipids (Thomas et al., 1984; Breuer et al., 2012; Mus et al., 2013), whereas under N-limitation (which means a reduced but constant availability of nitrogen) cells react with an increased synthesis of carbohydrates instead of proteins (Plumley and Darley, 1985; Geider et al., 1998; Jakob et al., 2007; Chauton et al., 2013). In the latter case the cells may face the problem that the 
biosynthesis of carbohydrates consumes less electrons per carbon (4 electrons/C) compared to proteins where the electron demand per $\mathrm{C}$ is around 6 (Kroon \& Thoms, 2006). Under Nlimited conditions, the electron sink by the assimilation of nitrate to proteins is reduced and the reductants are funnelled to carbohydrates. Since the capacity for carbohydrate storage is limited additional energy dissipation mechanisms are needed. The accumulation of reducing equivalents would force a cellular redox poise including an increased degree of reduction of the PQ pool (Guerra et al., 2013). For P. tricornutum it was shown that the redox state of the PQ pool is also involved in the activation of $\mathrm{CET}_{\text {PSII }}$ (Lavaud, 2007).

The $\mathrm{CET}_{\mathrm{PSII}}$ is an electron flow within PSII which does not contribute to water oxidation but re-donates electrons to the reaction center by intrinsic components of PSII. Thus, this cyclic electron path can be detected as an oxygen deficit during a sequence of single-turnover flashes (Lavaud et al., 2002). The function of the $\mathrm{CET}_{\mathrm{PSII}}$ is mainly seen as an additional electron sink which opens an energy-dissipating leak within the reaction centers of PSII (Feikema et al., 2006). Typically, this 'valve' would be opened under high light conditions when even under high non-photochemical dissipation of absorbed energy the linear electron flow might not be able to prevent an overreduction of $\mathrm{Q}_{\mathrm{A}}$, the primary electron acceptor of PSII (Lavaud, 2007). In this way, CET $_{\text {PSII }}$ could prevent photoinhibition of PSII reaction centers (Miyake and Okamura, 2003; Lavaud, 2007).

Recently, it was demonstrated that in P. tricornutum changes in the macromolecular cell composition, namely an increased synthesis of carbohydrates at the expense of proteins, coincided with a significantly higher degree of reduction of the PQ pool (Jungandreas et al., 2014). It could be, therefore, hypothesized that a change in the macromolecular composition due to N-limitation will influence the degree of reduction of the PQ pool and thus, will also trigger the activation state of the $\mathrm{CET}_{\mathrm{PSII}}$.

In the present study, we investigated the extent of alternative electron consumption, the activation state of the PSII cycle, the degree of reduction of the PQ pool, and the 
macromolecular composition of $P$. tricornutum under $\mathrm{N}$-limited conditions in combination with dynamic light conditions (high light irradiance at midday). It is expected that this combination forces the cells to re-balance their metabolism by changes of the macromolecular composition and changes in the photosynthetic apparatus, namely an increased energy dissipation by alternative electron sinks. It is further hypothesized that the preferred accumulation of carbohydrates under N-limitation could change the redox state of the PQ pool and thus, triggers the activation state of the $\mathrm{CET}_{\mathrm{PSII}}$. 


\section{Materials and methods}

\section{Culture Conditions}

The continuous cultivation of the diatom P. tricornutum (SAG 1090-1a, Culture Collection Göttingen, Germany; accession number CCMP2557 (DeMartino et al., 2007) was performed in a cyclostat (Kroon et al., 1992) with computer controlled light conditions at $20^{\circ} \mathrm{C}$ and 10/14 hours day/night cycles. The cultivation was operated at a culture volume of $2.6 \mathrm{~L}$. Illumination was provided by a high-intensity light source (HQI-1000 W-Daylight, Osram, Germany). To simulate natural light conditions with a daily course of sunlight a sinoidal light climate (SL) was applied with a daily photon fluence rate of $14.5 \mathrm{~mol} \mathrm{~m} \mathrm{~m}^{-2}$ and a maximum irradiance of approx. $1000 \mu \mathrm{mol} \mathrm{m} \mathrm{m}^{-2} \mathrm{~s}^{-1}$ (Suppl. Fig. S1). Self-shading of the cells was

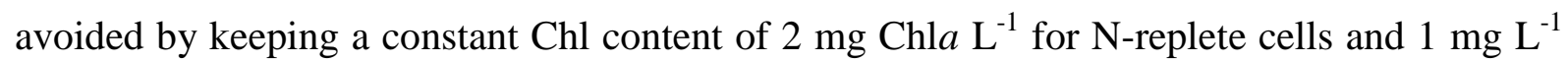
for N-limited cells.

Cells were grown in a continuous mode in modified artificial seawater medium (ASP2, Provasoli et al., 1975) with $\mathrm{N}$ concentrations of $11.8 \mathrm{mM}$ (N-replete conditions). Nitrate limited conditions were achieved by lowering the concentration of nitrate in the growth medium to $0.59 \mathrm{mM}$ which changed the culture conditions from a turbidostat mode under $\mathrm{N}$ replete conditions into a chemostat mode. Experiments were started after 7 to 10 days when the cells reached steady-state conditions (constant Chl per cell content for at least 3 days).

Biomass production rates (mg dry matter $\mathrm{L}^{-1} \mathrm{~d}^{-1}$ ) were calculated from:

$$
\text { Biomass production }=\mu \times \mathrm{DM}
$$

where $\mu$ is the daily growth rate $\left(\mathrm{d}^{-1}\right)$ and $\mathrm{DM}$ is the content of dry matter $\left(\mathrm{mg} \mathrm{L}^{-1}\right)$. For the gravimetric determination of dry matter content, $80 \mathrm{~mL}$ cell suspension was harvested by centrifugation $\left(4,000 \times \mathrm{g}, 5 \mathrm{~min}, 4^{\circ} \mathrm{C}\right)$, washed twice with distilled water and freeze-dried (Labconco FreeZone 2,5; Ilmvac GmbH, Ilmenau, Germany).

\section{Pigment analysis}


The concentration of Chla was determined spectrophotometrically in $90 \%$ acetone extracts using the equation of Jeffrey \& Humphrey (1975). Algal samples (5 mL) were collected on glass-fibre filters (Schleicher and Schuell, Dassel, Germany), $2.5 \mathrm{~mL}$ acetone added, and cells broken in a cell homogenizer (Braun, Melsungen, Germany). After centrifugation (1 min, 13.000 x $g$, Hermle, Z231, Gosheim, Germany), absorbance spectra were recorded with a spectrophotometer (Hitachi U2000, Tokyo, Japan).

\section{Estimation of alternative electron transport rates}

The amount of alternative electron transport rates were estimated by simultaneous measurement of fluorescence- $\left(P_{\mathrm{F}}\right)$ and oxygen-based $\left(P_{\mathrm{O}}\right)$ photosynthesis rates. A detailed description of the method is provided in Wagner et al. (2006). Basically, it is assumed that $P_{\mathrm{F}}$ represents the amount of all electron released at PSII, whereas the measured oxygen evolution $P_{\mathrm{O}}$ represents those electrons which are finally used for carbon assimilation. The difference $\left(P_{\mathrm{F}}-P_{\mathrm{O}}\right)$ is an estimate of the amount of alternative electron transport (AET) rates. These alternative electron sinks comprise mainly $\mathrm{O}_{2}$-consuming processes, like Mehler reaction, photorespiration, or cyclic electron transport (Schreiber \& Neubauer, 1990).

\section{Measurements of chlorophyll fluorescence parameters}

The extent of NPQ in response to the dynamic light conditions was determined by 'online fluorescence' that was measured directly at the surface of the culture vessel (according to Lippemeier et al., 2001) using a pulse amplitude modulated (PAM) fluorometer (unit 101/103, Walz, Effeltrich, Germany). Every $60 \mathrm{~s}$ a light pulse $\left(0.8 \mathrm{~s}, 4000 \mu \mathrm{mol}\right.$ photons $\mathrm{m}^{-2} \mathrm{~s}^{-1}$; KL1500, Schott, Germany) was given and the fluorescence parameters were recorded on a computer. NPQ was calculated according to Schreiber et al. (1994):

$$
\mathrm{NPQ}=\frac{\mathrm{F}_{\mathrm{m}}-\mathrm{F}_{\mathrm{m}}{ }^{\prime}}{\mathrm{F}_{\mathrm{m}}{ }^{\prime}}
$$


where $F_{m}$ and $F_{m}$ ' are the maximal fluorescence values in darkness and under actinic illumination, respectively.

The degree of reduction of PSII can be calculated as an approximate as $1-\mathrm{q}_{\mathrm{P}}$ according to equation (3) where $\mathrm{q}_{\mathrm{P}}$ is an approximation of the relative fraction of open PSII (Bradbury and Baker, 1984).

$$
1-\mathrm{q}_{\mathrm{P}}=\frac{\left(\mathrm{F}_{\mathrm{s}}{ }^{\prime}-\mathrm{F}_{0}{ }^{\prime}\right)}{\left(\mathrm{F}_{\mathrm{m}}{ }^{\prime}-\mathrm{F}_{0}{ }^{\prime}\right)}
$$

The fluorescence parameters were derived from P-I-curves measured hourly during the light period on samples taken directly from the culture vessel (for a detailed description see Wagner et al., 2006) with $\mathrm{F}_{\mathrm{s}}{ }^{\prime}$ as steady-state fluorescence under actinic illumination and $\mathrm{F}_{0}$ ' as minimal fluorescence of illuminated cells. The parameter $F_{0}$ ' is usually attained after actinic illumination and by selective excitation of PSI by far-red illumination. Alternatively, $\mathrm{F}_{0}$ ' can be estimated according to Oxborough and Baker (1997):

$$
\mathrm{F}_{0}{ }^{\prime}=\frac{1}{\left(\frac{1}{\mathrm{~F}_{0}}-\frac{1}{\mathrm{~F}_{\mathrm{m}}}+\frac{1}{\mathrm{~F}_{\mathrm{m}}{ }^{\prime}}\right)}
$$

where $\mathrm{F}_{0}$ is the minimal fluorescence in dark-adapted samples.

Fast fluorescence induction kinetics were recorded with a Plant Efficiency Analyzer (PEA, Hansatech, Norfolk, England) as described in Srivastava et al. (1995) in combination with a liquid adapter. The light intensity of the saturating light flash (1 s duration) was set to 3500 $\mu \mathrm{mol} \mathrm{m} \mathrm{m}^{-2} \mathrm{~s}^{-1}$. Fluorescence data were normalized to the respective initial and maximum fluorescence value of each measurement. Typically, the fluorescence transient of fast induction kinetics drives Chl fluorescence through two inflections points: $\mathrm{J}$ (after about $2 \mathrm{~ms}$ ) and I (after 30-50 ms). The J-level is supposed to reflect the light-driven accumulation of reduced $\mathrm{Q}_{\mathrm{A}}$ (Strasser et al., 1995). Since $\mathrm{Q}_{\mathrm{A}}$ is in redox equilibrium with the PQ pool, the Jlevel also represents an estimate of changes in the reduction state of the PQ pool (Tóth et al., 2007). Thus, the increase if the J-level is correlated with a more reduced PQ pool. In a dark- 
adapted state, this could be due to electron donation from sources located in the chloroplast stroma (e.g. Schansker et al., 2005). Fast fluorescence induction was measured from darkadapted samples prior the onset of daily illumination.

The normalized area over the fluorescence induction curve $\left(\mathrm{S}_{(\mathrm{t})}\right)$ was calculated according to Strasser et al. (2004):

$$
\mathrm{S}_{(t)}=\frac{\mathrm{S}_{t}}{\mathrm{~S}_{\max }}
$$

with $\mathrm{S}_{t}=\int_{0}^{t}(\mathrm{Fm}-\mathrm{F} t) d t$

where $S_{\mathrm{t}}$ (normalized complementary area) is the integral of the area between the fluorescence transient and the horizontal line at $\mathrm{F}=\mathrm{F}_{\mathrm{m}}$ and the vertical line at time $t . \mathrm{S}_{\max }$ is the total complementary area at $\mathrm{F}_{\mathrm{m}}$. Practically, $t=t_{\mathrm{Fm}}$ when $\mathrm{F}_{\mathrm{m}}$ was achieved.

\section{Flash induced oxygen evolution}

Flash induced oxygen evolution was measured polarographically by a home-built Joliot type bare platinum electrode (Joliot and Joliot, 1968). Algal samples were concentrated by centrifugation (14.000 x $g, 2 \mathrm{~min}$, Centrifuge 5417C, Eppendorf) to a final Chl $a$ concentration of $20 \mathrm{mg} \mathrm{L}^{-1}$. Measurements were started after a settling period of $7 \mathrm{~min}$ in darkness by a series of short ( $5 \mu \mathrm{s})$ saturating light flashes (Strobotac, General Radio) fired at $2 \mathrm{~Hz}$.

The oxygen flash yield of dark-adapted cells shows a period 4 oscillation with flash number due to the 4-state oxidation cycle of the oxygen-evolving complex (Joliot et al., 2003). Within a series of 20 flashes this oscillation will be damped to a constant steady state yield ( $\left.\mathrm{Y}_{\mathrm{SS}}\right)$ due to 'double hits' and 'misses'.

According to Lavaud et al. (2002) the oxygen deficit was quantified by:

Oxygen deficit $=\frac{\left\lfloor\left(20 \times \mathrm{Y}_{\mathrm{SS}}\right)-\sum_{1}^{20} \mathrm{O}_{2} \text { evolution }\right\rfloor-\left[\left(20 \times \mathrm{Y}_{\mathrm{SS}}\right)-\sum_{1}^{20} \mathrm{O}_{2} \text { evolution }\right\rfloor}{\text { dark }}$ 
where $\sum_{1}^{20} \mathrm{O}_{2}$ evolution is the sum of oxygen evolution measured during the application of all 20 flashes. Under all growth conditions samples were taken prior to the start of the light periods. From these the sample with the lowest measured oxygen deficit (indicated by 'dark') was used to normalize all other measurements.

\section{Elemental and macromolecular composition}

The elemental composition was measured according to Wagner et al. (2006) using a CHNSO analyser (vario EL, Analytik Jena GmbH, Germany).

The macromolecular composition of the cells with respect to proteins, carbohydrates and lipids was analyzed by Fourier transformed infrared (FTIR) spectroscopy as described in detail in Wagner et al. (2010). Briefly, during the light periods, samples were taken hourly from the culture vessel. From the washed and concentrated cell suspension, samples of $1 \mu \mathrm{L}$ (with $\sim 5 \times 10^{5}$ cells) were placed on a microtiter plate and dried at $40^{\circ} \mathrm{C}$ for $10 \mathrm{~min}$. IR-spectra were recorded in the range of $4000-700 \mathrm{~cm}^{-1}$ without further sample treatment in transmission mode with 32 scans oversampling to enhance the signal-to-noise ratio (Vector 22, HTS-XT microtiter module, OPUS v5.0 software, Bruker Optics, Germany). Spectral quota of proteins, carbohydrates, and lipids were quantified according to Wagner et al. (2010).

The daily synthesis rates of carbohydrates and proteins [pg cell ${ }^{-1} \mathrm{~d}^{-1}$ ] were calculated on the basis of the cellular fraction of macromolecules in P. tricornutum at 8.00 daytime and the respective growth rates under all experimental conditions.

\section{Statistics}

For statistical analysis the Student's t-test was used for the comparison of two data sets. The $\mathrm{p}$-values are marked with $*(\mathrm{p} \leq 0.05), * *(\mathrm{p} \leq 0.01)$ and $* * *(\mathrm{p} \leq 0.001)$. The amount of replicates (n) for each experiment is specified in the figure legends. 


\section{Results}

\section{Growth rates and $N$ assimilation rates}

The cultivation of $P$. tricornutum in a chemostat mode under $\mathrm{N}$-limitation reduced growth rates to appr. $50 \%$ in comparison to nutrient replete conditions (Table 1). The daily $\mathrm{N}$ assimilation rates were estimated from the biomass (BM) production rates and the BM:N ratio. The limited $\mathrm{N}$ supply in the medium reduced the $\mathrm{N}$ assimilation rate from $195 \mu \mathrm{mol} \mathrm{L}^{-1}$

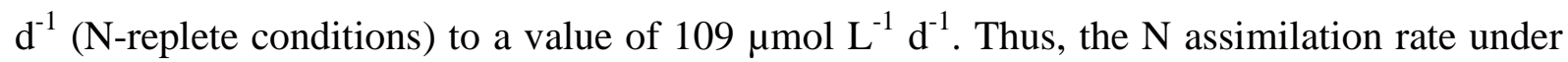
$\mathrm{N}$-limited conditions exactly matches the $\mathrm{N}$ supply by the medium and proves that growth of P. tricornutum was restricted by nitrogen availability.

\section{Alternative electron transport, PSII cycle activity and NPQ}

Figure 1a depicts the daily course of alternative electron transport (AET) rates expressed as percentage of fluorescence-based photosynthesis rates $\left(P_{\mathrm{F}}\right)$. Under N-replete conditions, AET rates showed a fast increase during the first $3 \mathrm{~h}$ of daily illumination in response to the incident irradiance and reached a plateau at 11.00 daytime which corresponds to an incident light intensity of approximately $500 \mu \mathrm{mol} \mathrm{m} \mathrm{m}^{-2}$ (see suppl. Fig. S1a). With the lowering of incident irradiance to values below $300 \mu \mathrm{mol} \mathrm{m} \mathrm{m}^{-2} \mathrm{~s}^{-1}(16.00-18.00)$ the (AET) rates decreased again. Under N-limited conditions, the daily course of AET rates was changed in two aspects in comparison to N-replete conditions: i) AET rates were generally higher and ii) particularly at the beginning of daily light period (time point 8.15) the AET rates were significantly higher under $\mathrm{N}$-limitation whereas at the end of the illumination period (time point 17.45) similar AET rates were measured under N-replete and N-limited conditions, respectively.

The cyclic electron transport at PSII (CET $\mathrm{CSII}_{\text {) }}$ is considered to be a fraction of AET since the active $\mathrm{CET}_{\mathrm{PSII}}$ decreases the oxygen evolution rate at PSII. The activity of $\mathrm{CET}_{\mathrm{PSII}}$ was detected by the measurement of oxygen flash yield induced by a series of single-turnover 
flashes. Within the application of 20 flashes a period four oscillation (representing the fourstep redox cycle of the oxygen evolving complex; OEC) is damped to a steady-state yield due to a miss-probability of about $10 \%$ and thus, a loss of synchrony of the redox states of the OEC. Typically, an activated $\mathrm{CET}_{\mathrm{PSII}}$ leads to a decreased oxygen flash yield within the first flashes (upto 15 flashes) as shown in Lavaud et al. (2002). It is assumed that the recovery of the oxygen yield at the end of the flash series is due to the oxidation of the PQ pool by PSI activity induced by the single-turnover flashes itself (Lavaud et al., 2002). Therefore, it should be emphasized that the oxygen deficit does not reflect a certain amount of alternative electrons used for $\mathrm{CET}_{\mathrm{PSII}}$ (Feikema et al., 2006).

In the present study, the daily course of the measured oxygen deficit was used as an indicator of the activation state of $\mathrm{CET}_{\mathrm{PSII}}$. It was found that the daily course of the oxygen deficit was comparable to the course of AET rates under both, N-replete and N-limited conditions (Fig. 1b). It is particularly evident that the oxygen deficit was higher under N-limitation in comparison to N-replete conditions for most of the light period. Notably, at the beginning of the illumination period significantly higher values of oxygen deficit were measured in $\mathrm{N}$ limited cells, whereas at the end of the light period no differences were observed in the comparison of $\mathrm{N}$-limited and $\mathrm{N}$-replete cells, respectively. This, again, is similar to the comparison of AET rates at the end of the illumination period in N-limited and N-replete cells, respectively. The similarity of the daily course of the oxygen deficit and the AET rates is further supported by the linear correlation of the respective values as shown in Fig. 2.

The non-photochemical quenching (NPQ) of fluorescence is an indicator of the degree of thermal dissipation of excessively absorbed light energy. Typically, increased values of NPQ can be observed under illumination with saturating light intensities (from 11.00-16.00 daytime; Fig. 3). The maximum values of NPQ were found to be slightly (but not significantly) higher and started at lower irradiance in the N-limited cells. 


\section{Fast fluorescence induction kinetics}

As describe above, an increased activation state of CET $_{\text {PSII }}$ was observed at the end of the dark period in $\mathrm{N}$-limited cells of $P$. tricornutum. To prove a possible linkage of CET $\mathrm{PSII}_{\mathrm{I}}$ activity with the degree of reduction of the PQ pool, measurements of fast fluorescence induction $(\Delta \mathrm{t}<1 \mathrm{~s})$ have been performed. The normalized fluorescence kinetics clearly revealed a faster increase of the fluorescence signal and an increased J-level (time point between 2 to $3 \mathrm{~ms}$ ) in dark-adapted cells under N-limitation in comparison to control cells under nutrient replete conditions (Fig. 4). The faster rise of fluorescence induction yielded in a significantly smaller area over curve in N-limited cells compared to N-replete cells. (Tab. 2). Moreover, the maximum quantum yield of PSII was significantly decreased from 0.58 to 0.36 in N-limited cells in comparison to cells grown under N-replete conditions (Tab. 2).

\section{Macromolecular composition}

In dependence on the nutrient condition, cells of $P$. tricornutum possessed a very different macromolecular composition already at the start of the light period (Table 3; time point 8.00). Whereas the fraction of lipids remained constant for all experimental conditions, N-limited cells showed an increased relative content of carbohydrates while the fraction of proteins was decreased in comparison to cells under nutrient replete conditions. This resulted in a drastically increased carbohydrate/protein ratio of 2.6 in N-limited cells compared to a ratio of 0.56 under nutrient replete conditions (Fig. 5). Generally, cells showed a preferred synthesis of carbohydrates at the expense of protein synthesis during the light period between time points 8.00 and 18.00 (Table 3) which resulted in a further increase of the carbohydrate/protein ratio during illumination under both, N-replete and N-limited conditions (Fig. 5).

It should be emphasized that the cultures were grown as continuous cultures. This means that even under N-limitation the cultures were in a steady state. Thus, the changes in the 
carbohydrate/protein ratios described above were observed during the day cycle and accumulated carbohydrates had to be converted into proteins during the dark period (time points 18.00 to 8.00 ) to reach the same macromolecular composition at the start of the light period again. Figure 6 depicts the daily synthesis rates of proteins and carbohydrates. Under nutrient replete conditions, the synthesis rate of proteins was almost twice as high as the respective synthesis rate of carbohydrates. This stands in clear contrast to $\mathrm{N}$-limited conditions where the carbohydrate synthesis rate was only slightly reduced, whereas the protein synthesis rate was significantly decreased by about $75 \%$ compared to nutrient replete conditions. As a result, the daily protein synthesis rate under $\mathrm{N}$-limited conditions reached only $40 \%$ of the carbohydrate synthesis rate. 


\section{Discussion}

\section{Dissipation of excess energy under dynamic light conditions}

Dynamic light conditions pose a challenge to the acclimation performance of microalgae because the kinetics of these changes are faster than metabolic responses e.g. by gene regulation or protein turnover. Therefore, under these conditions the acclimation process has to rely on fast regulatory mechanisms, namely NPQ and alternative electron consumption in diatoms. Thus, it is not surprising that the time course of NPQ values follows the changes of irradiance under sine light conditions. A comparable pattern was observed in the daily course of the amount of alternative electrons. The basic hypothesis of this study was that nitrogen limitation changes the balance between cellular energy uptake by light absorption and energy usage by the cellular metabolism (Geider et al., 1998). Consequently, a shift of this balance in favour of light absorption should increase the excitation pressure on the photosynthetic apparatus (Cleveland and Perry, 1987) at least at the onset of the period of decreased nitrogen supply. Under nitrogen limitation (reduced but constant supply of $\mathrm{N}$ ) the cells may regain energetic balance basically by a severe decrease of the cellular content of Chl a (Geider et al., 1998; Jakob et al., 2007). All experiments of the present study were performed under steadystate conditions of N-replete and N-limited conditions. It is therefore assumed that even under nitrogen limitation the cells were acclimated and in a nearly balanced energy state again (Geider et al., 1998). Nevertheless, under the applied dynamic light conditions and with respect to the changes in the macromolecular composition (see below) it could be expected that this balance between light absorption and metabolic energy consumption might exceed its limits under the high irradiance during midday. From the analysis of variable $\mathrm{Chl}$ fluorescence the degree of reduction of PSII can be approximated and indeed, a higher degree of PSII reduction was observed in N-limited cells during the period with irradiance intensity $>300 \mu \mathrm{mol}$ photons $\mathrm{m}^{-2} \mathrm{~s}^{-1}$ (Suppl. Fig. S2) which is well above the measured $\mathrm{I}_{\mathrm{k}}$ value of 
photosynthesis (data not shown). This result can be interpreted as an increased excitation pressure on PSII under $\mathrm{N}$-limited conditions in combination with strong irradiance. Consequently, a higher demand for energy dissipation, by e.g. NPQ and alternative electron pathways, could be expected under these conditions.

Interestingly, the time course of NPQ values did not change significantly under N-limited conditions. For the maximum values this could be due to the fact that already under N-replete conditions the maximum potential of this strain of $P$. tricornutum was exploited (compared to maximum NPQ values in Schumann et al., 2007).

In contrast however, the amount of alternative electron consumption was significantly increased during course of the light period under $\mathrm{N}$-limited conditions. This was accompanied by an increased activity of the $\mathrm{CET}_{\mathrm{PSII}}$ under N-limited conditions. Moreover, the plot of AET rate versus the measured oxygen deficit caused by $\mathrm{CET}_{\mathrm{PSII}}$ showed a linear correlation. From these results, it is likely to assume that the activated $\mathrm{CET}_{\mathrm{PSII}}$ significantly contributes to the total amount of alternative electron transport in $P$. tricornutum. Particularly under Nlimitation, the $\mathrm{CET}_{\mathrm{PSII}}$ could be an important sink for increased amount of excessively absorbed light energy. To our knowledge, such correlation was not shown so far for microalgae. This is a very important result since the quantification of specific alternative electron pathways (e.g. $\mathrm{CET}_{\mathrm{PSI}}$, Mehler reaction, photorespiration) in microalgae is methodologically very difficult and therefore often neglected. Nevertheless, it should be pointed out that the measurement of PSII oxygen deficit does not allow to directly conclude on the rate of cyclic electron transport at PSII and other alternative electron pathways might contribute to the observed effects. With respect to the energy balance of the cells under $\mathrm{N}$ limited conditions it could be concluded that the combination of decreased Chl content and increased alternative electron consumption was effective enough to re-balance energy supply by light absorption and energy consumption by cellular metabolism at least during the light period. 


\section{PSII cycle activity during light-to-dark transition in response to $\mathrm{N}$-limitation}

A surprising result of the present study was the observation of an increased amount of alternative electron consumption at the end of dark phase/beginning of the light period under N-limited conditions. This was correlated with an increased oxygen deficit at PSII measured during the dark-to-light transition. Thus, N-limited conditions significantly increased the CET $_{\text {PSII }}$ activity at the end of the dark phase and at the beginning of the daily light period in comparison to $\mathrm{N}$-replete conditions. In contrast, at the end of the light period no difference in the AET rate nor in the oxygen deficit between N-replete and $\mathrm{N}$-limited cells has been observed.

It was demonstrated that the activation of the $\mathrm{CET}_{\mathrm{PSII}}$ in $P$. tricornutum depends on an increased degree of reduction of the PQ pool (Feikema et al., 2006; Lavaud, 2007). Thus, it could be expected that this prerequisite for an activation of the $\mathrm{CET}_{\mathrm{PSII}}$ has to be fulfilled in N-limited cells of $P$. tricornutum at the end of the dark period. Indeed, the measurement of fast fluorescence induction kinetics revealed a significantly increased fluorescence rise under N-limited conditions. Thus, the increase of the J-level and the lowering of the area over the induction curve can be interpreted as an increased degree of reduction of the PQ pool (Strasser et al., 1995; Tóth et al., 2007). Such an increased degree of reduction of the PQ pool is not unusual in diatoms and was already observed under different experimental conditions e.g. during a light-to-dark transition (Dijkman and Kroon, 2002), under anaerobiosis (Cruz et al., 2011) or artificially in the presence of DCMU (Eisenstadt et al., 2008; Grouneva et al., 2009). In all cases, a chlororespiratory supply of electrons into the PQ pool by stromal reductants (e.g. NADPH) was assumed to be present in the investigated diatoms. Hence, the PQ pool appears to be influenced by the redox poise of the chloroplast in darkness (Wilhelm et al., 2014). 


\section{Macromolecular composition and cellular redox poise under $N$-limitation}

For the present study, it could be hypothesized that the change in the macromolecular composition of the cells under $\mathrm{N}$-limitation is related to a proposed increase of the redox poise of the chloroplast and to the observed increased degree of reduction of the PQ pool. Here, in particular, the daily pattern of carbon allocation into the different pools could be important. Under N-replete conditions, the photosynthetically assimilated carbon was preferentially stored as carbohydrates during the light period and redistributed into proteins during the dark phase. This resulted in a higher daily protein synthesis rate compared to the rate of carbohydrate synthesis which can be regarded as a common phenomenon in phytoplankton under diurnal light regimes (e.g. Foy and Smith, 1980; Vårum et al., 1986). Under N-limited conditions, there was a decreased but still preferred synthesis of carbohydrates during the light period. Nevertheless, the daily synthesis of proteins was drastically reduced. As a result, the synthesis rate $\left(\mathrm{pg}\right.$ cell $^{-1}$ ) of carbohydrates during the light period significantly exceeded the rate of dark protein synthesis which is similar to a study of Guerra et al. (2013).

The observed coincidence of changes in the macromolecular composition of the cells and changes in the degree of reduction of the PQ pool is similar to the study of Jungandreas et al. (2014) where the transition of P. tricornutum cells from illumination with blue light to red light induced a downregulation of protein synthesis but a stimulated synthesis of carbohydrates and an increase of the reduction of the PQ pool. According to Guerra et al. (2013), the shift of the carbon flux from proteins into carbohydrates caused an increase of the $\mathrm{NADPH} / \mathrm{NADP}^{+}$redox poise under $\mathrm{N}$-limited conditions. In turn, this implies a more reduced intracellular environment and a more reduced PQ pool (Guerra et al., 2013). According to Rosenwasser et al. (2014), the observed changes in the degree of reduction of the PQ pool under N-limitation could be further indication of a possible feedback mechanism to monitor the chloroplast redox state by the nitrate assimilation enzymes. 


\section{Conclusions}

The present study shows that $\mathrm{N}$-limitation induced an increased dissipation of photosynthetic energy by alternative electron transport in the diatom $P$. tricornutum under dynamic light conditions. From the linear correlation of AET rates and the activity of CET $_{\text {PSII }}$ it is concluded that the PSII cycle in P. tricornutum significantly contributes to AET. At the end of the dark period the difference in PSII cycle activity in the comparison of $\mathrm{N}$-limited and N-replete cells coincided with an increased degree of reduction of the PQ pool in cells under N-limitation. This is in line with previous publications where the activation of the PSII cycle in $P$. tricornutum was shown to be dependent on the degree of reduction of the PQ pool. In parallel with the increased degree of reduction of the PQ pool and enhanced activity of $\mathrm{CET}_{\mathrm{PSII}}$ at the end of the dark period, drastic changes in the carbon allocation pattern under $\mathrm{N}$-limitation in comparison to N-replete conditions were observed. Thus, the experimental conditions of this study provide a basis to elucidate if these observations could be involved in a feedback mechanism of redox regulation which is triggered by the macromolecular composition of the cells.

\section{Acknowledgments}

We thank the Deutsche Forschungsgemeinschaft (DFG) for financial support (grant numbers Wi 764/10, Wi 764/14 and Wi 764/19). J. Lavaud thanks the University of Konstanz, the DFG (grant LA 2368/2-1) and the CNRS for their financial support. 


\section{References}

Allen AE (2005) Defining the molecular basis for energy balance in marine diatoms under fluctuating environmental conditions. J Phycol 41:1073-1076

Allen AE, Dupont CL, Oborník M, Horák A, Nunes-Nesi A, McCrow JP, Zheng H, Johnson DA, Hu H, Fernie AR, Bowler C (2011) Evolution and metabolic significance of the urea cycle in photosynthetic diatoms. Nature 473:203-207

Armbrust EV, Berges JA, Bowler C, Green BR, Martinez D, Putnam NH, Zhou S, Allen AE, Apt KE, Bechner M, Brezinski MA, et al (2004) The genome of the diatom Thalassiosira pseudonana: Ecology, evolution, and metabolism. Science 306:79-86

Bender SJ, Parker MS, Armbrust EV (2012) Coupled effects of light and nitrogen source on the urea cycle and nitrogen metabolism over a diel cycle in the marine diatom Thalassiosira pseudonana. Protist 163:232-251

Bowler C, Allen AE, Badger JH, Grimwood J, Jabbari K, Kuo A, Maheswari U, Martens C, Maumus F, Otillar RP, Rayko E, et al (2008) The Phaeodactylum genome reveals the evolutionary history of diatom genomes. Nature 456:239-244

Breuer G, Lamers PP, Martens DE, Draaisma RB, Wijffels RH (2012) The impact of nitrogen starvation on the dynamics of triacylglycerol accumulation in nine microalgae strains. Bioresource Technology 124:217-226

Chauton MS, Olsen Y, Vadstein O (2013) Biomass production from the microalga Phaeodactylum tricornutum: Nutrient stress and chemical composition in exponential fedbatch cultures. Biomass and Bioenergy 58:87-94

Claquin P, Kromkamp JC, Martin-Jezequel V (2004) Relationship between photosynthetic metabolism and cell cycle in a synchronized culture of the marine alga Cylindrotheca fusiformis (Bacillariophyceae). Eur J Phycol 39:33-41

Cleveland JS, Perry MJ (1987) Quantum yield, relative specific absorption and fluorescence in nitrogen-limited Chaetoceros gracilis. Mar Biol 94:489-497

Cruz S, Goss R, Wilhelm C, Leegood R, Horton P, Jakob T (2011) Impact of chlororespiration on non-photochemical quenching of chlorophyll fluorescence and on the 
regulation of the diadinoxanthin cycle in the diatom Thalassiosira pseudonana. J Exp Bot 62:509-519

De Martino A, Meichenin A, Shi J, Pan K, Bowler C (2007) Genetic and phenotypic characterization of Phaeodactylum tricornutum (Bacillariophyceae) accessions. J Phycol 43:992-1009

Dijkman NA, Kroon BMA (2002) Indications for chlororespiration in relation to light regime in the marine diatom Thalassiosira weissflogii. J Photochem Photobiol B 66:179-187

Dimier C, Corato F, Tramontano F, Brunet C (2007) Photoprotection and xanthophyll-cycle activity in three marine diatoms. J Phycol 43:937-947

Eisenstadt D, Ohad I, Keren N, Kaplan A (2008) Changes in the photosynthetic reaction centre II in the diatom Phaeodactylum tricornutum result in non-photochemical fluorescence quenching. Environ Microbiol 10:1997-2007

Falkowski PG, Katz ME, Knoll AH, Quigg A, Raven JA, Schofield O, Taylor FJR (2004) The evolution of modern eukaryotic phytoplankton. Science 305:354-360

Feikema WO, Marosvölgyi MA, Lavaud J, van Gorkom HJ (2006) Cyclic electron transfer in photosystem II in the marine diatom Phaeodactylum tricornutum. Biochim Biophys Acta $1757: 829-834$

Foy RH, Smith RV (1980) The role of carbohydrate accumulation in the growth of planktonic Oscillatoria species. Brit Phycol J 15:139-150

Geider RJ, MacIntyre HL, Graziano LM, McKay RML (1998) Responses of the photosynthetic apparatus of Dunaliella tertiolecta (Chlorophyceae) to nitrogen and phosphorus limitation. Eur J Phycol 33:315-332

Genty B, Briantais J-M, Baker NR (1989) The relationship between the quantum yield of photosynthetic electron transport and quenching of chlorophyll fluorescence. Biochim Biophys Acta 990:87-92

Giordano M, Chen Y-B, Koblizek M, Falkowski PG (2005) Regulation of nitrate reductase in Chlamydomonas reinhardtii by the redox state of the plastoquinone pool. European Journal of Phycology 40:345-352 
Grouneva I, Jakob T, Wilhelm C, Goss R (2009) The regulation of xanthophyll cycle activity and of non-photochemical fluorescence quenching by two alternative electron flows in the diatoms Phaeodactylum tricornutum and Cyclotella meneghiniana. Biochim Biophys Acta 1787:929-938

Guerra LT, Levitan O, Frada MJ, Sun JS, Falkowski PG, Dismukes GC (2013) Regulatory branch points affecting protein and lipid biosynthesis in the diatom Phaeodactylum tricornutum. Biomass and Bioenergy 59:306-315

Hockin NL, Mock T, Mulholland F, Kopriva S, Malin G (2012) The response of diatom central carbon metabolism to nitrogen starvation is different from that of green algae and higher plants. Plant Physiol 158:299-312

Jakob T, Wagner H, Stehfest K, Wilhelm C (2007) A complete energy balance from photons to new biomass reveals a light- and nutrient-dependent variability in the metabolic costs of carbon assimilation. J Exp Bot 58:2101-2112

Jeffrey SW, Humphrey GF (1975) New spectrometric equations for determining chlorophylls $\mathrm{a}, \mathrm{b}, \mathrm{c} 1$ and $\mathrm{c} 2$ in higher plants, algae and natural phytoplankton. Biochem Physiol Pflanz 167:191-194

Joliot P (2003) Period-four oscillations of the flash-induced oxygen formation in photosynthesis. Photosynth Res 76:65-72

Joliot P, Joliot A (1968) A polarographic method for detection of oxygen production and reduction of Hill reagent by isolated chloroplasts. Biochim Biophys Acta 153:625-634

Jungandreas A, Schellenberger Costa B, Jakob T, von Bergen M, Baumann S, Wilhelm C (2014) The acclimation of Phaeodactylum tricornutum to blue and red light does not influence the photosynthetic light reaction but strongly disturbs the carbon allocation pattern. PLoS ONE 9:e99727

Kroon BMA, Hes UM, Mur LR (1992) An algal cyclostat with computer-controlled dynamic light regime. Hydrobiologia 238:63-70

Kroon BMA, Thoms S (2006) From electron to biomass: A mechanistic model to describe phytoplankton photosynthesis and staedy-state growth rates. J Phycol 42:593-609 
Lavaud J (2007) Fast regulation of photosynthesis in diatoms: Mechanisms, evolution and ecophysiology. Funct Plant Sci Biotech 1:267-287

Lavaud J, van Gorkom H, Etienne A-L (2002) Photosystem II electron transfer cycle and chlororespiration in planktonic diatoms. Photosynth Res 74:51-59

Lavaud J, Goss R (2014) The peculiar features of non-photochemical fluorescence Quenching in diatoms and brown algae. In: Demmig-Adams B, Garab G, III WA, Govindjee, editor(s). Non-photochemical quenching and energy dissipation in plants, algae and cyanobacteria. Springer Netherlands; 2014. p. 421-443.

Lippemeier S, Hintze R, Vanselow K, Hartig P, Colijn F (2001) In-line recording of PAM fluorescence of phytoplankton cultures as a new tool for studying effects of fluctuating nutrient supply on photosynthesis. Eur J Phycol 36:89-100

Lomas MW, Glibert PM (1999) Temperature regulation of nitrate uptake: A novel hypothesis about nitrate uptake and reduction in cool-water diatoms. Limnol Oceanogr 44:556-572

Miyake C, Okamura M (2003) Cyclic electron flow within PSII protects PSII from its photoinhibition in thylakoid membranes from spinach chloroplasts. Plant Cell Physiol $44: 457-462$

Mus F, Toussaint J-P, Cooksey KE, Fields MW, Gerlach R, Peyton BM, Carlson RP (2013) Physiological and molecular analysis of carbon source supplementation and $\mathrm{pH}$ stress-induced lipid accumulation in the marine diatom Phaeodactylum tricornutum. Applied Microbiology and Biotechnology 97:3625-3642

Oxborough K, Baker NR (1997) Resolving chlorophyll a fluorescence images of photosynthetic efficiency into photochemical and non-photochemical components calculation of qP and Fv'/Fm' without measuring Fo'. Photosynthesis Research 54:135-142

Plumley FG, Darley WM (1985) Interactions of light/dark cycles and nitrogen pulses on the timing of cell division in the nitrogen-limited marine diatom Cylindrotheca fusiformis (Bacillariophyceae). J Phycol 21:25-34

Provasoli L, McLaughlin JJA, Droop MR (1957) The development of artificial media for marine algae. Arch Mikrobiol 25:392-428 
Raven JA, Geider RJ (2003) Adaptation, acclimation and regulation in algal photosynthesis. In: Larkum AWD, Douglas SE, Raven JA, editor(s). Photosynthesis in Algae. Springer Netherlands; 2003. p. 385-412.

Rosenwasser S, Creveld SG van, Schatz D, Malitsky S, Tzfadia O, Aharoni A, Levin Y, Gabashvili A, Feldmesser E, Vardi A (2014) Mapping the diatom redox-sensitive proteome provides insight into response to nitrogen stress in the marine environment. PNAS 111:2740 2745

Schansker G, Tóth SZ, Strasser RJ (2005) Methylviologen and dibromothymoquinone treatments of pea leaves reveal the role of photosystem I in the Chl a fluorescence rise OJIP. Biochim Biophys Acta 1706:250-261

Schreiber U, Bilger W, Neubauer C (1994) Chlorophyll fluorescence as a nonintrusive indicator for rapid assessment of in vivo photosynthesis. In: Ecophysiology of photosynthesis. Springer Berlin Heidelberg; 1994. p. 49-70.

Schreiber U, Neubauer C (1990) O2-dependent electron flow, membrane energization and the mechanism of non-photochemical quenching of chlorophyll fluorescence. Photosynth Res 25:279-293

Schumann A, Goss R, Jakob T, Wilhelm C (2007) Investigation of the quenching efficiency of diatoxanthin in cells of Phaeodactylum tricornutum (Bacillariophyceae) with different pool sizes of xanthophyll cycle pigments. Phycologia 46:113-117

Smith SR, Abbriano RM, Hildebrand M (2012) Comparative analysis of diatom genomes reveals substantial differences in the organization of carbon partitioning pathways. Algal Res $1: 2-16$

Srivastava A, Strasser RJ, Govindjee (1995) Polyphasic rise of chlorophyll a fluorescence in herbicide-resistant D1 mutants of Chlamydomonas reinardtii. Photosynth Res 43:131-141

Strasser RJ, Srivastava A, Govindjee (1995) Polyphasic chlorophyll a fluorescence transient in plants and cyanobacteria. Photochem Photobiol 61:32-42

Strasser RJ, Tsimilli-Michael M, Srivastava A (2004) Analysis of the Chlorophyll a Fluorescence Transient. In: Papageorgiou GC, Govindjee, (eds) Chlorophyll a Fluorescence, Springer, The Netherlands, pp 321-362 
Thomas WH, Seibert DLR, Alden M, Neori A, Eldridge P (1984) Yields, photosynthetic efficiencies and proximate composition of dense marine microalgal cultures. I. Introduction and Phaeodactylum tricornutum experiments. Biomass 5:181-209

Vårum KM, Østgaard K, Grimsrud K (1986) Diurnal rhythms in carbohydrate metabolism of the marine diatom Skeletonema costatum (Grev.) Cleve. J Exp Mar Biol Ecol 102:249-256

Wagner H, Jakob T, Wilhelm C (2006) Balancing the energy flow from captured light to biomass under fluctuating light conditions. New Phytol 169:95-108

Wagner H, Liu Z, Langner U, Stehfest K, Wilhelm C (2010) The use of FTIR spectroscopy to assess quantitative changes in the biochemical composition of microalgae. J Biophotonics 3:557-566

Wilhelm C, Jungandreas A, Jakob T, Goss R (2014) Light acclimation in diatoms: From phenomenology to mechanisms. Marine Genomics 16:5-15 


\section{Tables}

Table 1: Growth rates, biomass production rates, ratio biomass per nitrogen, estimated Nassimilation rate in $P$. tricornutum under $\mathrm{N}$-replete and $\mathrm{N}$-limited conditions. The amount of nitrogen supplied by continuous medium inflow in the culture vessel ( $\mathrm{N}$ supply) was calculated according to the growth rates and the respective dilution rate. To yield N-limited conditions the $\mathrm{N}$ concentration in the medium was reduced to $0.59 \mathrm{mM}$. Data are given as mean values $(\mathrm{n}=3-10)$ and standard deviation (in parenthesis).

\begin{tabular}{lcc}
\hline & N-replete & N-limited \\
\hline Growth rate $\mu\left[\mathrm{d}^{-1}\right]$ & $0.35(0.02)$ & $0.18(0.01)$ \\
Dry matter content $\left[\mathrm{mg} \mathrm{mg} \mathrm{Chl}{ }^{-1}\right]$ & $45(3)$ & $178(18)$ \\
Biomass production rate $\left[\mathrm{mg} \mathrm{L}^{-1} \mathrm{~d}^{-1}\right]$ & $31.2(1.5)$ & $32.1(0.4)$ \\
Biomass : $\mathrm{N}\left[\mathrm{g} \mathrm{g}^{-1}\right]$ & $11.6(0.8)$ & $20.9(1.3)$ \\
$\mathrm{N}$-assimilation rate $\left[\mu \mathrm{mol} \mathrm{L} \mathrm{d}^{-1}\right]$ & $195(13)$ & $109(6)$ \\
$\mathrm{N}$ supply $\left[\mathrm{mmol} \mathrm{L}^{-1} \mathrm{~d}^{-1}\right]$ & $4.1(0.2)$ & $0.11(0.01)$ \\
\hline
\end{tabular}


Table 2: Parameters derived from fast fluorescence induction measurements in dark-adapted cells of P. tricornutum: Maximum quantum yield of PSII (Fv/Fm) and normalized area over curve. Data are given as mean values $(n=6-10)$ and standard deviation (in parenthesis).

\begin{tabular}{lll}
\hline & N-replete & N-limited \\
\hline Fv/Fm & $0.58(0.01)$ & $0.36(0.01)$ \\
Area over curve & $0.23(0.01)$ & $0.10(0.01)$ \\
\hline
\end{tabular}


Table 3: Macromolecular composition of cells of $P$. tricornutum at the beginning $(08.00$ daytime) and at the end (18.00 daytime) of the daily light period under exponentially fluctuating (FL) and sinusoidal light (SL) in combination with nutrient replete and N-limited conditions. Macromolecular composition of the biomass with respect to proteins, carbohydrates, lipids (percentage of dry matter). Values of cellular dry matter are depicted as pg per cell. Data are given as mean values and standard deviation (in parenthesis) of at least three independent replicates.

\begin{tabular}{llll}
\hline & & N-replete & N-limited \\
\hline Proteins & 08.00 & $57(0.5)$ & $25(0.4)$ \\
& 18.00 & $45(0.9)$ & $21(1.6)$ \\
Carbohydrates & 08.00 & $32(5.1)$ & $64(0.1)$ \\
& 18.00 & $43(1.0)$ & $69(2.4)$ \\
Lipids & 08.00 & $10(1.3)$ & $11(0.4)$ \\
& 18.00 & $12(0.5)$ & $10(1.2)$ \\
\hline
\end{tabular}




\section{Legends of figures}

Figure 1: a) Alternative electron transport (AET) rates and b) extent of the oxygen deficit in Phaeodactylum tricornutum during the course of the light period in the comparison of Nreplete (filled squares) and N-limited (open circles) growth conditions. AET rates are depicted as percentage of fluorescence-based photosynthesis rates $\left(\mathrm{P}_{\mathrm{F}}\right)$. Data are presented as mean values and standard deviation $(n=3-4)$.

Figure 2: Linear correlation of alternative electron transport (AET) rates versus oxygen deficit in Phaeodactylum tricornutum. Data were derived from mean values of measurements under N-replete and N-limited conditions.

Figure 3: Representative example of the course of non-photochemical quenching (NPQ) in cells of Phaeodactylum tricornutum during the course of the light period under N-replete (closed squares) and $\mathrm{N}$-limited conditions (open circles).

Figure 4: Representative example of fast fluorescence induction kinetics of dark-adapted cells of Phaeodactylum tricornutum cultivated under N-replete (filled squares) and N-limited (open circles) conditions. The dotted line indicates the J-level of fluorescence induction after about 2 ms.

Figure 5: Comparison of changes in the carbohydrate/protein ratio $\left(\mathrm{pg}^{\mathrm{pg}}{ }^{-1}\right)$ in Phaeodactylum tricornutum during the course of the light period under N-replete (filled squares; left y-axes) and $\mathrm{N}$-limited conditions (open circles; right y-axes). Data are presented as mean values and standard deviation of three independent measurements. Note the different scaling of y-axes which was adjusted to display comparable relative changes of values. 
Figure 6: Calculated daily synthesis rate $\left(\mathrm{pg}\right.$ cell $\left.^{-1} \mathrm{~d}^{-1}\right)$ of proteins (filled columns) and carbohydrates (open columns) in cells of Phaeodactylum tricornutum under N-replete and Nlimited conditions.

Supplemental Figure S1: Photosynthetically available radiation (PAR) under dynamic light conditions during a $10 \mathrm{~h}$ light period: left) non-fluctuating sine light climate (SL); right) exponentially fluctuating light conditions (FL).

Supplemental Figure S2: Approximate degree of reduction of Photosystem II expressed as $\left(1-q_{P}\right)$ of nutrient replete (filled squares) and nitrogen limited cells (open circles) of Phaeodactylum tricornutum. 